\title{
HFOV in Pediatric ARDS: Viable or Vestigial?
}

\author{
Muralidharan Jayashree $^{1}$ (D) $\cdot$ CR Vishwa $^{1}$
}

Received: 24 January 2020 / Accepted: 24 January 2020 / Published online: 5 February 2020

(C) Dr. K C Chaudhuri Foundation 2020

Pediatric acute respiratory distress syndrome (PARDS) is associated with significant mortality [1], more so in the low middleincome countries (LMIC) [2-5]. Furthermore, mortality is proportional to the severity of ARDS; $1-15 \%$ for mild and moderate ARDS and 33\% for severe ARDS [6]. Over the years, several therapeutic strategies have evolved with the hope to reduce ARDS related mortality. These include low tidal volume lung protective ventilation, high frequency oscillatory ventilation (HFOV), airway pressure release ventilation (APRV), prone ventilation, nitric oxide, surfactant therapy, steroids and extracorporeal membrane oxygenation (ECMO). Among these, HFOV has been used as a 'rescue' or 'salvage therapy' for hypoxemia refractory on conventional mechanical ventilation (CMV). Pediatric acute lung injury consensus conference (PALICC) guidelines recommend use of $\mathrm{HFOV}$ in patients with moderate to severe ARDS with a $\mathrm{P}_{\text {Plat }}>28 \mathrm{~cm} \mathrm{H}_{2} \mathrm{O}$ [7].

Theoretically, HFOV has an edge over CMV as it delivers smaller tidal volumes and causes less cyclical atelectotrauma due to a continuous distending pressure [8]. These advantages have however not translated into mortality benefits $[9,10]$. A systematic review of 10 RCT's in adults showed that HFOV neither reduced hospital stay nor $30 \mathrm{~d}$ mortality [11]. Another meta-analysis of 6 RCT's in children with a total of 246 PARDS patients, failed to demonstrate significant reduction in duration of ventilation or mortality despite improved oxygenation parameters [12]. Some of the reasons postulated for this lack of benefit with HFOV were timing of transition (early vs. late) and disease and patient related factors. Contrary to the postulated theoretical benefits, one meta-analysis in adults in fact showed abnormal hemodynamic profile and barotrauma related to HFOV [13].

Given the above background, the findings reported by Chattopadhyay et al. are relevant; more so because data

Muralidharan Jayashree

mjshree@hotmail.com

1 Division of Pediatric Critical Care, Advanced Pediatrics Centre, PGIMER, Chandigarh, India related to HFOV from India is limited. The authors have described 34 children with ARDS and refractory hypoxemia in whom they have assessed timing of HFOV and determinants of survival [14]. They found that improvement in oxygenation index (OI) at $48 \mathrm{~h}$ of initiation of HFOV along with percent increase in $\mathrm{PaO}_{2} / \mathrm{FiO}_{2}$ ratio at $24 \mathrm{~h}$ determined survival. These findings are similar to a previous study which had demonstrated $24 \mathrm{~h}$ OI to be a better predictor of survival [15].

Timing of transition to HFOV has been a contentious issue and studies are divided on this. Some have shown better survival with early as compared to late HFOV, while others have negated this [16]. In the index study too, the authors did not find any difference in mortality between early and late HFOV. However, the duration of CMV before transitioning to HFOV was higher in non-survivors $[62 \mathrm{~h}(12,144)$ vs. $30-25 \mathrm{~h}(12,96)]$ as compared to survivors, suggesting a delayed transition. The duration of CMV prior to transition is known to impact the effectivity of HFOV [17]; lesser duration of CMV, means lesser degree of ventilator induced lung injury (VILI). Early HFOV could possibly help in better recruitment and lower VILI.

In developing countries, ARDS mortality is usually contributed by the non-pulmonary organ involvement, independent of the type of ventilation $[2,3]$. Of these acute kidney injury and fluid overload are a lethal combination $[18,19]$. In the current study, although a lower sequential organ failure assessment (SOFA) score was associated with survival benefit, more details about the different non-pulmonary organ dysfunctions and proportion of children with nosocomial infection could have helped us understand the reasons for death better.

In LMIC, ECMO is out of reach for many due to its limited availability and exorbitant running costs. Short of ECMO, many centers still rely on HFOV for PARDS, which fails conventional ventilation. Ideally HFOV, with its low tidal volumes, should prevent ARDS mortality. However current available evidence is unable to corroborate this. Future prospective studies focusing more stringently on timing of transition, patient and disease related factors may yield answers. Till that time, it may be premature to write off HFOV in PARDS. 


\section{Compliance with Ethical Standards}

Conflict of Interest None.

\section{References}

1. Wong JJ-M, Jit M, Sultana R, et al. Mortality in pediatric acute respiratory distress syndrome: a systematic review and meta-analysis. J Intensive Care Med. 2019;34:563-71.

2. Prasertsan P, Anuntaseree W, Ruangnapa K, Saelim K, Geater A. Severity and mortality predictors of pediatric acute respiratory distress syndrome according to the pediatric acute lung injury consensus conference definition. Pediatr Crit Care Med. 2019;20:e464-72.

3. Yadav B, Bansal A, Jayashree M. Clinical profile and predictors of outcome of pediatric acute respiratory distress syndrome in a PICU: a prospective observational study. Pediatr Crit Care Med. 2019;20:e263-73.

4. Lodha R, Kabra SK, Pandey RM. Acute respiratory distress syndrome: experience at a tertiary care hospital. Indian Pediatr. 2001;38:1154-9.

5. Gupta S, Sankar J, Lodha R, Kabra SK. Comparison of prevalence and outcomes of pediatric acute respiratory distress syndrome using pediatric acute lung injury consensus conference criteria and Berlin definition. Front Pediatr [Internet]. 2018. https://doi.org/10.3389/ fped.2018.00093.

6. Khemani RG, Smith L, Lopez-Fernandez YM, et al. Paediatric acute respiratory distress syndrome incidence and epidemiology (PARDIE): an international, observational study. Lancet Respir Med. 2019;7:115-28.

7. Pediatric acute respiratory distress syndrome: consensus recommendations from the pediatric acute lung injury consensus conference. Pediatr Crit Care Med. 2015;16:428-39.

8. Hupp SR, Turner DA, Rehder KJ. Is there still a role for highfrequency oscillatory ventilation in neonates, children and adults? Exp Rev Respir Med. 2015;9:603-18.

9. Young D, Lamb SE, Shah S, et al. High-frequency oscillation for acute respiratory distress syndrome. N Engl J Med. 2013;368:806-13.
10. Ferguson ND, Cook DJ, Guyatt GH, et al. High-frequency oscillation in early acute respiratory distress syndrome. N Engl J Med. 2013;368:795-805.

11. Sud S, Sud M, Friedrich JO, et al. High-frequency oscillatory ventilation versus conventional ventilation for acute respiratory distress syndrome. Cochrane Database Syst Rev [Internet]. 2016 Apr 4. Available at: http://doi.wiley.com/10.1002/14651858.CD004085. pub4. Accessed 19 Jan 2020.

12. Qiao JY, Li YZ, Wang HY, Zhang SD. [A Meta analysis of the efficacy of high-frequency oscillatory ventilation versus conventional mechanical ventilation for treating pediatric acute respiratory distress syndrome] Article in Chinese. Zhongguo Dang Dai Er Ke Za Zhi. 2017;19:430-435.

13. Huang C-T, Lin H-H, Ruan S-Y, Lee M-S, Tsai Y-J, Yu C-J. Efficacy and adverse events of high-frequency oscillatory ventilation in adult patients with acute respiratory distress syndrome: a meta-analysis. Crit Care. 2014;18:R102.

14. Chattopadhyay A, Gupta S, Sankar J, Kabra SK, Lodha R. Outcomes of severe PARDS on high-frequency oscillatory ventilation - a single centre experience. Indian J Pediatr. 2020. https://doi. org/10.1007/s12098-019-03134-9.

15. Yehya N, Servaes S, Thomas NJ. Characterizing degree of lung injury in pediatric acute respiratory distress syndrome. Crit Care Med. 2015;43:937-46.

16. Bateman ST, Borasino S, Asaro LA, et al. Early high-frequency oscillatory ventilation in pediatric acute respiratory failure. A propensity score analysis. Am J Respir Crit Care Med. 2016;193:495-503.

17. Camporota L, Sherry T, Smith J, Lei K, McLuckie A, Beale R. Physiological predictors of survival during high-frequency oscillatory ventilation in adults with acute respiratory distress syndrome. Crit Care. 2013;17:R40.

18. Valentine SL, Sapru A, Higgerson RA, et al. Fluid balance in critically ill children with acute lung injury. Crit Care Med. 2012;40:2883-9.

19. Ingelse SA, Wösten-van Asperen RM, Lemson J, Daams JG, Bem RA, van Woensel JB. Pediatric acute respiratory distress syndrome: fluid management in the PICU. Front Pediatr. 2016;4:21. https:// doi.org/10.3389/fped.2016.00021.

Publisher's Note Springer Nature remains neutral with regard to jurisdictional claims in published maps and institutional affiliations. 